\title{
A New Measure to Assess Psychopathic Personality in Children: The Child Problematic Traits Inventory
}

\author{
Olivier F. Colins • Henrik Andershed • Louise Frogner • \\ Laura Lopez-Romero • Violaine Veen • \\ Anna-Karin Andershed
}

Published online: 13 September 2013

(C) The Author(s) 2013. This article is published with open access at Springerlink.com

\begin{abstract}
Understanding the development of psychopathic personality from childhood to adulthood is crucial for understanding the development and stability of severe and longlasting conduct problems and criminal behavior. This paper describes the development of a new teacher rated instrument to assess psychopathic personality from age three to 12 , the Child Problematic Traits Inventory (CPTI). The reliability and validity of the CPTI was tested in a Swedish general population sample of 2,056 3- to 5-year-olds (mean age $=3.86$; $\mathrm{SD}=.86 ; 53 \%$ boys). The CPTI items loaded distinctively on three theoretically proposed factors: a Grandiose-Deceitful Factor, a Callous-Unemotional factor, and an Impulsive-Need for Stimulation factor. The three CPTI factors showed reliability in internal consistency and external validity, in terms of expected correlations with theoretically relevant constructs (e.g., fearlessness). The interaction between the three CPTI factors was a stronger predictor of concurrent conduct problems than any of the three individual CPTI factors, showing
\end{abstract}

\section{O. F. Colins}

Curium-LUMC, Department of Child and Adolescent Psychiatry,

Leiden University, Endegeesterstraatweg 27, 2342 AK Oegstgeest,

The Netherlands

e-mail: o.colins@curium.nl

O. F. Colins $\cdot$ H. Andershed $(\varangle) \cdot$ L. Frogner $\cdot$ A.-K. Andershed School of Law, Psychology, and Social Work, Örebro University, 701 82 Örebro, Sweden

e-mail: henrik.andershed@oru.se

\section{Lopez-Romero}

Facultad de Psicología - Campus Vida - Dpto. de Psicología Clínica y

Psicobiología, Universidad de Santiago de Compostela,

15782 Santiago de Compostela, Spain

e-mail: laura.lopez.romero@usc.es

\section{Veen}

Violaine Veen, Clinical Child and Adolescent Studies, Leiden University, P.O. Box 9555, 2300 RB Leiden, The Netherlands

e-mail: v.c.veen@fsw.leidenuniv.nl that it is important to assess all three factors of the psychopathic personality construct in early childhood. In conclusion, the CPTI seems to reliably and validly assess a constellation of traits that is similar to psychopathic personality as manifested in adolescence and adulthood.

Keywords Assessment $\cdot$ Child problematic traits inventory (CPTI) · Children · Conduct problems · Psychopathic personality

\section{Introduction}

Many studies have shown that psychopathic personality, or psychopathy, as it is usually termed when used among adults, is measurable and related to frequent and severe conduct problems and criminal behavior in late childhood and adolescence (Lynam et al. 2009; Salekin 2008; Salekin and Lynam 2010). Therefore, understanding the development and stability of psychopathic personality from early childhood to adulthood may well be one of the most important missions for research aimed to understand the determinants of severe and long-lasting criminal behavior. An important question that subsequently arises, is how far down in ages this construct is measurable, and not the least, what psychopathic traits can (or cannot) be measured really early in life. In this paper, we describe the conceptual background and development of a new measure, the Child Problematic Traits Inventory (CPTI), and test its psychometric properties.

Different Conceptualizations and Theories of Psychopathic Personality in Youths

Adult psychopathy is described as a syndrome comprising a constellation of extreme interpersonal, affective and behavior/ lifestyle traits that co-occur together (Andershed et al. 2002; 
Cooke and Michie 2001). Indeed, several studies on adolescents and adults have identified individuals with psychopathic personality using all of these dimensions of the adult psychopathy construct. These studies, for example, showed that youths high on all three dimensions have more conduct problems, and have committed more offenses than youths low on all three dimensions or high on only one dimension (e.g., Andershed et al. 2008; Colins et al. 2012; Vincent et al. 2003).

Most psychopathy research in youths focus on only one lower-order factor of psychopathic personality or they study all lower-order factors as separate dimensions rather than to consider them as parts of a syndrome (Andershed 2010). One line of research that is given substantial attention in the literature stems from the work of Frick and colleagues (Frick and Dickens 2006; Frick and White 2008). These researchers consider the affective (or callous-unemotional, CU) dimension of the psychopathic personality to be the most important dimension for identifying a group of antisocial and conduct disordered youths with a high risk for severe and long-lasting conduct problems and supposedly fledgling psychopathic personality. Linked to CU traits is a theory stating that fearless children develop CU traits because they are less sensitive to punishment and therefore will have difficulties to develop adequate forms of guilt and empathy (Frick 2009; Frick and Viding 2009; Pardini 2006).

Another approach for identifying fledgling psychopaths by focusing on one dimension stems from Lynam's (1996) theory. He suggested that tomorrows adult psychopaths are most likely to be found in children and adolescents that have both Conduct Disorder (CD) and Attention Deficit/Hyperactivity Disorder (AD/HD) (Lynam 1996). This theory suggests that the behavioral dimension of the psychopathic personality construct is the most important to identify antisocial children and adolescents on a developmental pathway towards psychopathy in adulthood.

Although the CU line of research has significantly contributed to the unraveling of pathways to $\mathrm{CD}$ and serious antisocial behavior, our concern is that $\mathrm{CU}$ traits have become increasingly synonymous with psychopathic personality. Also, it is important to test if the CU dimension alone is actually better than the combination of all dimensions of the psychopathic personality in predicting conduct problems. Indeed, studies show that youths high on all three dimensions exhibit more conduct problems than youths high only on the CU dimension (Christian et al. 1997; Colins et al. 2012).

\section{Conceptual Model and Guiding Principles of the CPTI}

In developing the CPTI, the idea was to test whether it was possible to assess a construct of psychopathic personality in childhood, including early childhood, that closely resembles how it is usually conceptualized and assessed in adolescence and adulthood, often with three or four dimensions (e.g., Andershed et al. 2002; Cooke and Michie 2001; Neumann et al. 2007). We did not consider the four factor model of psychopathic personality (e.g., Neumann, et al. 2007) because it was decided that the CPTI should not include traits or behaviors that are closely related to or even overlapping conceptually with rule-breaking, conduct problems, and antisocial behavior. This was decided because we wanted the CPTI to be a measure to assess psychopathic traits that in turn can be used to understand and predict conduct problems (see more below). Specifically then, the CPTI was aimed to measure a childhood version of the three-factor model of psychopathic personality (e.g., Andershed et al. 2002; Cooke and Michie 2001) rather than a single dimension such as the $\mathrm{CU}$ dimension.

Except for the decision to focus on the three factor model of psychopathic personality, two more principles guided our work in choosing which traits of the three factors to include in the CPTI. The first principle was that only those traits that have theoretical and/or empirical support for being applicable and assessable in children from three to 12 years of age within the framework of the three factor model conceptualization should be included. In our literature review, presented in the next section, we found no compelling theoretical or empirical arguments to support the possibility that the traits parasitic lifestyle, lack of realistic long term goals, and glibness/superficial charm can be meaningfully assessed in childhood. Therefore, these traits were not included in the CPTI. The second principle was that the CPTI should not include traits that are closely related to or even overlapping conceptually with rule-breaking, conduct problems, and antisocial behavior. This was decided to avoid issues with contamination when using the CPTI as a measure of psychopathic personality in research aimed at understanding the development of conduct problems. Thus, the traits irresponsible behavior and failure to accept responsibility for one's own actions and other antisocial features, such as the antisocial facet of the construct in the Psychopathy Checklist-Revised (Hare 2003), were not included in the CPTI.

Theories and Empirical Studies of Assessable Psychopathic Traits in Childhood

\section{The Interpersonal Dimension of the Psychopathic Personality in Childhood}

This dimension of the psychopathic personality typically refers to traits such as lying, manipulation, deceitfulness, dishonesty, grandiosity, and glibness/superficial charm (Cooke and Michie 2001). As mentioned above, the guiding principles of the CPTI led to the exclusion of glibness/superficial charm from this dimension, but can the rest of these traits be measured in childhood?

Lying has been defined as making a false statement with the intention to deceive another individual (Lee 2000). Successful lying involves the capacity to take the visual perspective of others (e.g., Bigelow and Dugas 2008), theory-of-mind understanding 
(e.g., Hala et al. 1991; Pollak and Harris 1999), good executive functioning such as working memory (e.g., what did I do and what did I say I did) and inhibition (e.g., suppressing statements that contradict the lie) (e.g., Talwar and Lee 2008). Three-yearolds are capable of verbally deceiving others (e.g., Lewis et al. 1989) and to lie strategically (e.g., Fu et al. 2012), and they often deliberately attempt to mislead (Pollak and Harris 1999). Lying and deceiving are not necessarily problematic behaviors in a child, as they are, for example, also associated with normal cognitive development (Talwar and Lee 2008), and, thus, can be seen as normative in preschool children. This may raise questions whether lying should be part of the construct of psychopathic personality in early childhood. Yet, the fact that many adults lie on a day-to-day basis (Depaulo and Kashy 1998), does not say that it is invalid to include lying in the construct of adult psychopathy. This is because psychopaths differ from most adults regarding the frequency of telling lies, the readiness to lie, the apparent ease with which they tell lies, and the way they react when being confronted with their lie (e.g., lack of guilt or shame) Hare 2003; Lee et al. 2008). There is evidence that a group of preschoolers are identified as chronic liars (StouthamerLoeber 1986). Thus, there is some evidence that even preschool children are able to lie when given the opportunity (Hala et al. 1991), although only a smaller group of children seems to lie much more than is considered normative by their teachers and parents. Therefore, we included items in the CPTI aimed to assess lying.

Adult psychopaths often have a grandiose sense of selfimportance and overrate their own competencies and skills (Vitacco and Kosson 2010). Therefore, they often present themselves as superior to others in interpersonal interactions, and are often perceived by others as arrogant, self-indulgent and dominant individuals who brag and want to impress others. A disorder that shares many of the psychopathic traits captured under the interpersonal dimension of the psychopath construct is narcissistic personality disorder (Hart and Hare 1998). Even though research on the early manifestations of narcissism is in its infancy (Thomaes et al. 2009), it has been shown that narcissistic traits, such as an urge to be the center of attention, and to be very sure of oneself, can be reliably measured in early childhood (Carlson and Gjerde 2009; Cramer 2011; Scholte et al. 2011; Scholte and van der Ploeg 2007). In addition, narcissistic traits, as measured at age three, have been shown to predict narcissism in young adulthood (Carlson and Gjerde 2009; Cramer 2011). Thus, there is evidence that inflated feelings of self-worth are observable already from age three. Therefore, we included items in the CPTI aimed to assess grandiosity.

\section{The Affective Dimension of the Psychopathic Personality in Childhood}

Psychopathic traits included under the affective or CU dimension refer to lack of empathy, callousness, shallow affect, failure to accept responsibility for one's own actions, and lack of guilt or remorse (Cooke and Michie 2001). For this dimension, our guiding principles stated above excluded failure to accept responsibility for one's own actions as a relevant trait because it relates closely or even overlaps with irresponsible behavior and conduct problems.

Empathy has an affective component and a cognitive one (e.g., Decety et al. 2009; Shamay-Tsoory et al. 2009; Walter 2012). Affective empathy refers to a person's emotional response to the affective state of another individual and the sharing of emotions. Cognitive empathy refers to the capacity to understand what other people feel (Shamay-Tsoory et al. 2009). Empathy, thus, can broadly be defined as awareness and sharing of, and response to, the feelings of other human beings. Children as young as 6 months of age respond to emotional distress in peers. At age two, children respond to distress with a variety of helping behaviors, such as physical and verbal comfort, sharing, and distracting the person in distress (Zahn-Waxler et al. 1992). At age three, children are generally capable of a variety of empathy related behaviors, including expressing verbal and facial concern and interest in another's distress (McDonald and Messinger 2009). At age four, children already have the ability, and do efforts, to understand that a situation is distressing for someone else. They are able to recognize the other's emotions evoked by that situation, and to be emotionally responsive to the emotions expressed by others (Knafo et al. 2009; Singer 2006). In sum, empathy, and a lack thereof, seems measurable in childhood. Because affective empathy deficits, but not cognitive empathy deficits, has been considered and demonstrated to be a key feature of the psychopathic personality construct (Jones et al. 2010), we included items in the CPTI aimed to assess lack of affective empathy.

The concepts of callousness and shallow affect are closely related to the lack of empathy in psychopathic individuals. Whereas empathy involves a commission or expression of some feeling or behavior, callousness largely refers to the omission of caring feelings/behaviors when others generally experience those feelings/behaviors, and to an active disregard for others in distress expressed by, for example, enjoyment and hostility (Shirtcliff et al. 2009). In the psychopathy literature, shallow affect generally refers to being unable to experience a normal range and depth of emotions, and therefore individuals with this trait appear cold and unemotional (e.g., Hare 2003). Infants and toddlers are emotionally responsive to the emotions of others (e.g., sadness) (Bandstra et al. 2011) suggesting that shallow affect and being unemotional (cf. the lack of emotional responsiveness) can already be observed in preschoolers. Therefore, the CPTI includes items that assess these traits.

Guilt is generally seen as consequence of moral transgression (Tilghman-Osborne et al. 2010). This includes feelings of tension, remorse, and regret (Eisenberg 2000). In young children, 
researchers observe guilt by focusing on behavioral and affective signs of discomfort, such as avoidance, increased tension, and overall appearance of being affected (Koshanska et al. 2002 see also My Child Measure: Koshanska et al. 1994). Children who feel guilty and remorseful are also expected to display guiltrelevant behavior, such as trying to repair what is broken, confess or acknowledge that they were wrong, or apologize for their wrongdoing (Tilghman-Osborne et al. 2010). Guilt can be observed and measured very early in life. Twenty-two months old children have shown a highly coherent response that reflected tension (e.g., gaze aversion, bodily signals) when they believed they had committed a transgression (Koshanska et al. 2002). It has also been demonstrated that 3-year-old children showed reparation, are concerned about the good feelings of others and confess their wrongdoings (e.g., Koshanska et al. 1994). Based on this evidence, we included items in the CPTI aimed to assess lack of remorse and guilt.

\section{The Behavioral Dimension of the Psychopathic Personality in Childhood}

The behavioral dimension of the psychopathic construct includes psychopathic traits such as impulsivity, need for stimulation, sensation seeking, proneness to boredom, parasitic lifestyle, lack of realistic long term goals, and irresponsibility (Cooke and Michie 2001). Parasitic lifestyle, lack of realistic long term goals, and irresponsibility were considered nonrelevant according to the CPTI guiding principles. The remaining traits in this dimension are examined in this section.

Impulsive behavior is often defined as the inability to delay, inhibit, or control behavior (Chacko et al. 2009). Several overlapping but different concepts are used that refer to impulsive behavior, for example, disinhibition, referring to the disrupted ability to suppress one response in favor of a more non-dominant behavior (Dowsett and Livesey 2000); or selfregulation/effortful control, referring to capability of voluntary controlling one's behavioral impulses (Koshanska and Aksan 2006; Ponitz et al. 2009); or ADHD (APA 2000). These concepts can be measured in preschool children. Studies on inhibitory control show that between the age of 22 and 33 months, children develop simple skills, such as suppressing a motor response (Carlson 2005; Koshanska et al. 2000; Koshanska et al. 1996). Between 3 and 5 years of age, developmental spurts occur, where more complex inhibition skills are seen (Garon et al. 2008). For example, effortful control begins to emerge early in the second year of life, and becomes highly stable before the age of four (e.g., Koshanska et al. 2000). In studies on $\mathrm{AD} / \mathrm{HD}$, impulsive behaviors, such as difficulties awaiting turn, blurting out answers and interrupting or intruding others, can be measured in children as young as 3 years of age (Eggers and Angold 2006; Willoughby et al. 2012). While the above reviewed studies demonstrated that impulsive behavior can be expected in early childhood, only between one fifth and one third of these children display these behaviors very often (Willoughby et al. 2012). This clearly suggests that it is possible to identify a group of highly impulsive children in early childhood. Based on this, we included items in the CPTI aimed to assess impulsivity.

The psychopathic traits need for stimulation, sensation seeking, and proneness to boredom is closely related to the conceptualization of sensation seeking currently given attention in understanding risk taking and preventing injuries in children and adolescents. Sensation seeking in this research field is often defined by features such as seeking varied, novel, intense, arousing, and emotionally behavioral experiences that are accompanied by physical risk taking (Morrongiello et al. 2012). Although risky play may be normative in early childhood for some children (Sandseter and Kennair 2012), this body of research suggests that preschoolers with elevated levels of sensation seeking can reliably be identified. Measures of sensation seeking in older children, adolescents and adults sometimes include a dimension referring to the intolerance for monotonous, and repetitive events (i.e., boredom susceptibility or proneness to boredom) (e.g., Morrongiello and Lasenby 2006) and is likely possible to assess in early childhood as well. Therefore, the CPTI includes items that assess need for stimulation, sensation seeking, and proneness to boredom.

\section{Existing Instruments and the Need for Another One}

Several instruments that were specifically designed to assess psychopathic traits in children and adolescents are currently available (for a review see: Kotler and McMahon 2010). Yet, none of these instruments was designed for use in young children. Only one of these instruments, the Antisocial Process Screening Device (APSD; Frick and Hare 2001) allows for assessment of psychopathic traits in relatively young children (from age 6), whereas most other instruments were developed for use in late childhood (e.g., Youth Psychopathic Traits Inventory - Child Version; van Baardewijk et al. 2008) and/or adolescence (e.g., Childhood Psychopathy Scale; Lynam 1997b). The two APSD studies in preschool children that used all three (Dadds et al. 2005) or only the CU dimension (Kimonis et al. 2006) reported very low internal consistency of the APSD dimensions. Although the proposed bifactorial factor model of the Inventory of Callous Unemotional Traits (ICU; Essau et al. 2006) could not be replicated in 3-year-olds, CU traits were generally associated with variables of interest (e.g., effortful control, executive functioning (Ezpeleta et al. 2013). Also, the ICU does not assess features relating to the interpersonal dimension or the behavioral dimension of the psychopathic personality. Except for the APSD and the ICU, there are several recent attempts to develop assessment tools with the aim to measure psychopathic traits in childhood (Dadds et al. 2005; Scholte et al. 2011; Scholte and van der Ploeg 2007; Waller et al. 2012; 
Willoughby et al. 2011). However, none of these new tools are aimed at assessing the three-factor model of the psychopathic personality construct.

The Present Study: Aims and Hypotheses

The present study tests the psychometric properties of the CPTI (for details see Measures). Specifically, the first aim of this study was to test the internal, factorial validity of the CPTI. It was hypothesized that the fit for a three-factor structure of the CPTI would be good, or at least acceptable. Based on previous studies (e.g., van Baardewijk et al. 2008), we also expected a good to acceptable model fit across gender and age groups. We hypothesized that this three-factor model would show a better fit compared to a one factor model and a CU factor only model. Furthermore, we hypothesized that the three factors would be moderately to strongly correlated with each other.

The second aim was to test the reliability in form of internal consistencies of the three factors of the CPTI and the total score. It was hypothesized that the CPTI and its factors would show good to excellent internal consistencies, in the total group, in both genders and all age groups.

The third aim was to explore gender and age differences in the mean levels of the CPTI total score and its three factors. Based on previous studies (e.g., Colins et al. 2012; Frick et al. 2000; Scholte and van der Ploeg 2007), we expected higher levels on all three factors in boys than girls. We had an exploratory approach as to whether there were differences in the three CPTI factors between age groups.

The fourth aim was to test the external, criterion validity of the CPTI by examining its relation with external constructs of interest based theories (Frick and Viding 2009; Lynam 1997a), namely: Conduct Problems, AD/HD symptoms, and the temperamental dimensions Easy temperament and Fearlessness. It was hypothesized that the three factors of the CPTI and its total score would be significantly correlated, in terms of zero order correlations, with all of these constructs, albeit negatively with Easy temperament and that these correlations would hold even when controlling for the sociodemographic characteristics; gender, age, ethnic origin, and parents' socio-economic status. It was also hypothesized that partial correlations between the single CPTI factors (i.e., independent of the other two factors) and the external validity constructs would be weaker than the zero order correlations. This would indicate that the CPTI factors are dependent of each other in their relation to the external validity constructs and thus that the relation between the CPTI factors and the external validity constructs at least in part lies in the combination of all three CPTI factors.

The fifth aim also had to do with internal, criterion validity but involved focusing in more detail on the importance of the single CPTI factors versus the combinations of the three factors, in relation to conduct problems. It was hypothesized that the combination (i.e., interaction) of the three CPTI factors would be a better predictor of concurrent conduct problems than any single CPTI factor, supporting that all three factors are needed.

\section{Method}

The present study uses data from the first wave (i.e., first data collection) of the SOFIA-study (Social and Physical Development, Interventions and Adaptation), a prospective longitudinal research project that aims to better understand correlates, determinants, and the heterogeneity of the development of children's behavior, social adjustment, and psychological and physical health. This project also aims to describe and understand which children receive special support and interventions, and which do not. The target population of the SOFIA-study $(N=2,542)$ was all the children born between 2005 and 2007, and attending preschools during the spring of 2010 in a mid-sized Swedish municipality (Karlstad). With approximately 85,000 citizens, the demographics of this municipality are, in terms of proportion, similar with the rest of Sweden with regard to age, sex, education level, level of employment, and the mixture between urban and rural areas. About $10 \%$ of the children from the target population attended private schools. Both municipal and private preschools are divided into several departments depending on the age of the children. The departments usually hold between 10 and 30 children each, with a mean of about 18 children and three people in the staff, who typically have a formal preschool teacher university education. Data of the first wave of the study was collected through questionnaires answered by preschool teachers, parents/caregivers and principals/head masters of the preschool departments. The present study only relied on information from teachers and parents.

\section{Participants}

The participating children with ratings on the majority of the variables of focus in the present study were included in this paper. This resulted in 2,056 children (i.e., $80.1 \%$ of the target population) that were included in the present study $(1,087$; $52.9 \%$ boys and $969 ; 47.1 \%$ girls). Mean age of the participating children was 3.86 years $(\mathrm{SD}=.86)$. Specifically, 687 (33.4\%) were 3-year-olds, 687 (33.4\%) were 4-year-olds, and the remaining $682(33.2 \%)$ were 5-year-olds. In terms of origin, $18.4 \%$ out of the 2,056 children have at least one parent who was born in another country than Sweden.

Attrition Although $80.1 \%$ of the children from the target population were included in the present study, the remaining $19.9 \%$ were not involved because the parents actively said no or never responded at all to the information of the study, or because not 
enough answers were provided for the variables used in this study. To investigate whether the non-participating group differed on important dimensions from the participating group, 30 randomly chosen parents (from 15 girls and from 15 boys) were interviewed via telephone using a smaller number of questions from the parents'/caregivers' questionnaire. The analyses showed that it was significantly more common in the nonparticipating group that the mother was born outside Sweden (Cohen's $d=.71$ ) and that parents reported significantly less affection and praise toward their children (Cohen's $\mathrm{d}=.46$ ). However, the non-participating group did not differ significantly from the participating group concerning important dimensions such as conduct problems (Cohen's $\mathrm{d}=.02$ ), internalizing problems (Cohen's $\mathrm{d}=.26$ ), socio-economic status of the caregivers (Cohen's $\mathrm{d}=.48$ ), or the country of origin of the father and the child (Cohen's $\mathrm{d}=.31$ ). Moreover, no significant differences between the groups were found concerning parents' worries for their child's social development (Cohen's $\mathrm{d}=.11$ ) and several other dimensions of parenting (Cohen's $\mathrm{d}=$ =between .06 and .35 ).

\section{Measures}

Child Problematic Traits Inventory (CPTI) The aim with the CPTI was to develop a research instrument that enables longitudinal studies that test developmental theories and stability of psychopathic traits and psychopathic personality across different developmental phases. Therefore, the aim was to include items that can be used among both younger and older children. Specifically, the CPTI was developed with the intention to be a measure of psychopathic traits from age three to 12 . The items of the CPTI were developed using a theory-driven approach in the sense that they were developed based on the three-factor model of psychopathy and we developed items that we believed tapped the childhood manifestations of the psychopathic traits included in the three-factor model. Based on the literature review in the introduction concerning assessable traits in childhood and the two guiding principles of the CPTI (see introduction), grandiose sense of self-worth, lying, and deceitfulness was aimed to be assessed as the interpersonal dimension with a total of 8 items in the CPTI. This factor was labeled the Grandiose-Deceitful (GD) factor. Lack of remorse or guilt and callousness/lack of empathy was aimed to be assessed as the affective dimension with a total of 10 items. This factor was labeled the Callous-Unemotional (CU) factor. Need for stimulation/Sensation-seeking/Proneness to boredom, and Impulsivity were aimed to be assessed as the behavioral dimension with a total of 10 items. This factor was labeled the Impulsive-Need for Stimulation (INS) factor. All 28 items of the CPTI are presented in Table 1.

To increase the possibility to study the stability of psychopathic traits and psychopathic personality from childhood to adolescence and adulthood, we used the same 4-point Likert- type scale that has been used in the widely used Youth Psychopathic traits Inventory (Andershed et al. 2002), a selfreport questionnaire with generally good psychometric properties (e.g., internal consistency, good model fit for its three-factor structure, and good criterion validity) in late childhood (e.g., van Baardewijk et al. 2008), adolescence (e.g., Seals et al. 2012) and young adulthood (Neumann and Pardini 2012). The response scale of the CPTI is (coded in the data with the numbers preceding the respective scale steps): $1=$ Does not apply at all; 2=Does not apply well; $3=$ =Applies fairly well; and 4=Applies very well. On the first page of the questionnaire, information is given concerning the overall content of the items and that the rater should assess each item based on how the child usually and typically behaves rather than based on how he or she behaves at the moment. We developed the CPTI to be primarily rated by teachers. In the present study, the items of the CPTI were framed to comprise the behavior of the child during the last 6 months.

Conduct Problems This construct was assessed by parents and teachers through ten items that were developed especially for the present study, and were closely based on criteria of ODD and CD of the DSM-IV-TR (APA 2000) relevant to preschool children. Examples of items are: "Has been very angry", "Has violated important rules in preschool/at home", and "Has beaten, torn, shoved, kicked, or thrown something on others without a reason." Both teachers and parents rated the frequency of each of the ten items on the following response scale: $1=$ Never, $2=$ Rarely, 3 =Sometimes, $4=$ Often, $5=$ Very often . The items were framed to comprise the behavior of the child during the last 6 months. Cronbach's alphas were .93 and .83 of this scale for teachers and parents, respectively. The mean of the ten items was calculated for the teacher and parent rated items, respectively, to gain the two Conduct Problems variables used in the present study (i.e., teacher and parent rated Conduct Problems).

\section{Attention-Deficit/Hyperactivity Disorder (AD/HD) symptoms}

This construct was assessed by teachers using 18 items aimed to assess the diagnostic criteria of $\mathrm{AD} / \mathrm{HD}$ of the DSM-IV-TR (APA 2000) using DuPaul's AD/HD scale (DuPaul et al. 1998). Examples of items are: "He/she is running around, clutching or climbing more than what is considered appropriate" and "He/she is inattentive on details or is careless." The response scale is: $1=$ Never , $2=$ Seldom , $3=$ Sometimes, $4=$ Often , $5=$ Very Often. The items were framed to comprise the behavior of the child during the last 6 months. The Cronbach's alpha was 96 . The mean of the 18 items was calculated to gain the $\mathrm{AD} / \mathrm{HD}$ symptoms variable used in the present study.

Easy temperament This construct was assessed via three items developed especially for the present study and were rated by teachers on the following response scale; $1=$ Does not apply at all, 2=Applies poorly, 3=Applies fairly well, 4=Applies well . 
Table 1 Item loadings of a threefactor solution in the total sample as shown via an exploratory factor analysis with promax rotation along with cronbach's alphas of the three factors
Factor loadings larger than .40 are in boldface. $G D$ grandiose-deceitful factor; $C U$ callous-unemotional factor; INS impulsivity-need for stimulation factor. The number preceding the item indicates the order in which it is administered in the CPTI

\begin{tabular}{|c|c|c|c|}
\hline Item & GD & $\mathrm{CU}$ & INS \\
\hline 5 - Lies often to avoid problems & .96 & -.03 & -.06 \\
\hline 7 - Seems to see himself/herself as superior compared to others & .71 & .13 & .10 \\
\hline 9 - Often lies to get what he/she wants & .93 & .03 & -.03 \\
\hline 15 - Seems to lie more than other children of the same age & .90 & .07 & -.02 \\
\hline 18 - Is often superior and arrogant toward others & 67 & .26 & .02 \\
\hline 21 - To get people to do what he/she wants, he/she often finds it efficient to con them & .84 & -.02 & .09 \\
\hline 24 - Thinks that he/she is better than everyone at almost everything & .68 & .13 & .11 \\
\hline 26 - To frequently lie seems to be completely normal for him $/$ her & .88 & .11 & -.02 \\
\hline 2 - Seldom expresses sympathy for others & -.01 & .91 & -.08 \\
\hline 4 - Usually does not seem to share others' joy and sorrow & -.02 & .96 & -.11 \\
\hline 8 - Never seems to have bad conscience for things that he/she has done & .24 & .64 & .09 \\
\hline 11 - Often seems to be completely indifferent when other children are upset & .08 & .78 & -.01 \\
\hline 13 - Does not become upset when others are being hurt & .04 & .90 & -.04 \\
\hline 17 - Seldom remorseful when he/she has done something not allowed & .21 & .70 & .10 \\
\hline 20 - Often does not seem to care about what other people feel and think & .14 & .85 & -.01 \\
\hline 22 - Sometimes seems to completely lack the capability to feel guilt and remorse & .21 & .75 & .07 \\
\hline 25 - Never expresses feelings of guilt when he/she has done something not allowed & .21 & .76 & .02 \\
\hline $\begin{array}{l}27 \text { - Does not express guilt and remorse to the same extent as other children of the } \\
\text { same age }\end{array}$ & .17 & .81 & -.01 \\
\hline 1 - Likes change and that things happen all the time & .03 & -.32 & .87 \\
\hline 3 - Often has difficulties with awaiting his/her turn & -.13 & .15 & .85 \\
\hline 6 - Seems to do certain things just for the thrill of it & .36 & .01 & .53 \\
\hline 10 - Provides himself/herself with different things very fast and eagerly & .16 & -.03 & .74 \\
\hline 12 - Often does things without thinking ahead & .11 & .21 & .62 \\
\hline 14 - Often consumes things immediately rather than saving them & .13 & .09 & .57 \\
\hline 16 - Seems to have a great need for change and excitement & .20 & -.13 & .83 \\
\hline 19 - Does not like waiting & -.09 & .09 & .89 \\
\hline 23 - Seems to get bored quickly & -.03 & .10 & .82 \\
\hline 28 - Quickly gets tired of things and wants new things to happen all the time & -.13 & .00 & .97 \\
\hline \multicolumn{4}{|l|}{ Cronbach's alpha $(\alpha)$} \\
\hline Total sample & .91 & .95 & .92 \\
\hline Boys & .92 & .95 & .93 \\
\hline Girls & .90 & .94 & .91 \\
\hline 3 -year-olds & .89 & .95 & .93 \\
\hline 4-year-olds & .91 & .95 & .92 \\
\hline 5-year-olds & .92 & .95 & .92 \\
\hline
\end{tabular}

The three items are: "He/she is happy and positive", "He/she is a child who other children want to play with", and "He/she is easy and nice to be with". The items were framed to comprise the behavior of the child during the last 6 months. Cronbach's alpha was .82. The mean of the three items was calculated to gain the Easy temperament variable used in the present study.

Fearlessness This construct was assessed via six items that were developed especially for the present study and were rated by teachers. Examples of items are: "He/she does not seem to be afraid of anything", "He/she does not seem to be afraid when someone is trying to frighten him/her", and "He/she never seems to get scared when someone is mad at him/her." The response scale is: $1=$ Does not apply at all, 2=Applies poorly, 3=Applies fairly well, 4=Applies well. The items were framed to comprise the behavior of the child during the last 6 months. Cronbach's alpha was .89. The mean of the six items was calculated to gain the Fearlessness variable used in the present study.

Parents' SES and origin Parents' origin was assessed via one question to the parents, asking whether they were born in Sweden or not. Parents' SES was assessed via questions to the parents about their level of education and about their yearly 
income. The SES variable used in the present study was computed by first computing the mean of the two parents' educational level and then the mean of their yearly salary. Then these two means were z-transformed and a mean of these two z-scored means was computed to be the SES variable.

\section{Procedure}

All the procedures were evaluated and approved by an ethics committee (\#2009/429). The information about the study was first presented to the highest level of decisions makers in the Child and Adolescent Department of the municipality and to all preschool principals. It was decided, in political agreement that all municipal preschools would participate in the SOFIA study. The private schools were informed separately and the majority chose to participate. The data collection started with a gathering of all the staff of the schools, where they were presented with extensive information about the background, purpose, and procedure of the SOFIA study. Each preschool department enrolled a contact person for the study and was handed a folder containing information to the parents/ caregivers, along with user names and passwords to the web-questionnaire. The preschool teachers personally handed out the information to the parents/caregivers and the preschool departments. An active consent form was filled out by the caregivers and collected by the preschool teachers, who then could start to complete their questionnaires concerning the children they knew best at their preschool department. One teacher could answer the questionnaire for several children. Preschool teachers and parents had the opportunity to choose if they wanted to fill out the questionnaires via web or by paper. The questionnaires were in Swedish, but also translated to five different common languages in Sweden. A vast majority of the participants chose to fill out the questionnaires in Swedish and via the web. The questionnaire took about 20 min to complete for the preschool teachers and about $30 \mathrm{~min}$ for caregivers. After completing the questionnaires, caregivers were sent a gift voucher valid at many different stores and restaurants. Caregivers who were late in responding were reminded by preschool teachers and the staff of the study via telephone calls and letters. The preschool teachers answered the questionnaires as part of their daily work and did not receive any personal gratifications. All involved preschool staff was thanked at the end of the data collection via e-mail and a written letter, as well as with a small gift that was sent to all preschool departments.

\section{Statistical Analyses}

Exploratory Factor Analysis (EFA) was conducted to check the three-factor structure of the CPTI. Maximum-Likelihood (ML) method is usually used for model estimation. However, given the problem with inflated correlations when the items are not measured in a continuous scale (West et al. 1995), and the skewed distribution of the items in different directions, the ML estimation was inappropriate (Flora and Curran 2004). Previous studies suggested that Full Weighted Least Square (full WLS) and Robust Weighted Least Square (robust WLS) are good alternatives for these issues in the data (e.g., Flora and Curran 2004). However, there are several disadvantages with full WLS (e.g., the weighting matrix can be consistently non-positive and, thus, cannot be inverted, and the standard errors of parameters can be underestimated; Flora and Curran 2004), which lead us to use robust WLS as a method of model estimation to make the interpretation sensible. PROMAX was used as a rotation method in order to obtain correlated factors. With the aim to test and confirm the three-factor model of the CPTI, we performed Confirmatory Factor Analysis (CFA). Robust WLS was used again as a method of model estimation. Both EFA and CFA were conducted in Mplus 6.12 (Muthén and Muthén 2011).

The external validation of the CPTI was carried out in the following steps. First, we conducted zero-order correlations between the three CPTI factors and several behavioral, temperamental and familial variables. The correlation coefficients were interpreted following Cohen's guidelines (Cohen 1988; i.e., weak $=<.30$, moderate $=.30-.50$, and strong $=>.50$ ). Second, in order to partialling out the effect of some sociodemographical variables (i.e., children's Age, Gender, Parents' Origin, and Parents' SES), as well as the other two CPTI factors, we also calculated partial correlations. As a last step, we conducted as series of multiple regression analyses with concurrent Conduct Problems as the dependent variable to test to test the unique, additive, and interactional effects of the three CPTI factors on concurrent Conduct Problems.

\section{Results}

Internal Validity of the CPTI

Factorial Validity ${ }^{1}$ The first objective of the present study was to study the factorial validity, that is, the factor structure of the 28 items of the CPTI. Following the three-factor model of adult psychopathy (Cooke and Michie 2001), the proposed CPTI model is supposed to be composed of three interrelated

\footnotetext{
${ }^{1}$ Before the CPTI was administered to the participants in the current study, the CPTI was pilot tested twice in two independent samples of approximately 200 preschool children (age three to five years). Given the sample sizes it was not possible to reliably perform Confirmatory Factor Analysis. However, both pilot studies showed, via Exploratory Factor Analyses, that the CPTI items clearly and distinctively loaded on the three proposed factors. These factors had good internal consistency and were strongly correlated with variables of interest (e.g., conduct problems, AD/ HD symptoms, and temperament) (details available upon request from H.A.).
} 
first-order factors: Grandiose and Deceitful (GD), Callous and Unemotional (CU), and Impulsivity and Need for Stimulation (INS). These three factors were assumed to be correlated and affected by a common general factor, Psychopathic Personality.

As a first step, EFA was conducted on the 28 items of the CPTI. The scree plot clearly suggested three factors. The factor loadings of the three factors are presented in Table 1 and it shows that the CPTI items distinctively load on the three expected factors. As seen in Table 1, all items exhibit factor loadings above .40 on the expected factor and not one single item load above .40 on more than one factor. Moreover, as displayed in Table 1, the Cronbach's alphas for the GD, CU and INS factors were high, evidencing good internal consistencies of the three factors. Table 1 also shows that the Cronbach's alphas did not differ much across gender and age.

With the aim to test how well the proposed three-factor model of the CPTI fitted the current data, we conducted a series of CFAs. Given the principle of parsimony, which suggests that if two models have similar model fits to the same data the simpler model is preferred (Kline 2011; Schumacker and Lomax 2004), we also tested a one-factor model (including all 28 CPTI items). This single factor model would represent a sort of general psychopathic personality pattern. In addition, a CU-factor model was tested comprising one factor including the 10 items of the CPTI aimed to measure CU traits. This was done because of the wide use of the $\mathrm{CU}$ factor only in current research in children. Results of the CFAs testing these three competing models are presented in Table 2.

In terms of fit indices, RMSEA should be less than .08 (Browne and Cudeck 1993), or preferably less than .05 (Steiger 1990). CFI larger than .95 and TLI larger than .90, or ideally .95, are also considered to be good (Hu and Bentler 1999). As shown in Table 2, the one-factor model and the CUfactor model did not have acceptable model fits in the current

Table 2 Model fit indices based on confirmatory factor analyses of one-, $\mathrm{CU}$-, and three-factor models along with tests of the three-factor model among boys and girls and in the three age groups

\begin{tabular}{lclll}
\hline & N & RMSEA & CFI & TLI \\
\hline One-factor model & 1742 & .12 & .91 & .90 \\
CU-factor model & 1742 & .12 & .99 & .98 \\
Three-factor model & 1742 & .07 & .96 & .96 \\
Boys & 903 & .07 & .97 & .97 \\
Girls & 839 & .07 & .96 & .96 \\
3-year-olds & 591 & .07 & .98 & .97 \\
4-year-olds & 574 & .07 & .97 & .96 \\
5-year-olds & 577 & .07 & .97 & .97 \\
\hline
\end{tabular}

The N's are lower than 2,056 (the total sample) because of individual missing items. Estimation method is robust WLS. RMSEA root mean square error of approximation; $C F I$ comparative fit index; TLI tuckerlewis index data. The RMSEA of the three-factor model was however considerably smaller compared with the two other competing models, and lower than the suggested .08, and CFI and TLI were both larger than .95 . In sum, fit indices suggest that the three-factor model is the best model and that this model has an adequate to good fit to the data. We also wanted to test whether this adequate fit of the three-factor model held among both boys and girls and in the various age groups. However, we had the problem of inconsistent categorical values in the data, which occurs when the number of categories of an item is not the same across different subgroups. This prevented us from formally testing measurement invariance across gender and age groups. Instead, we tested the model fit of the three-factor model in each subgroup; the results are presented in Table 2. As seen, the fit indices did not vary much in the gender and age groups from those of the full dataset, suggesting an acceptable to good fit of the three-factor model in these subgroups.

The results of the three-factor model estimation in the total group are presented in Fig. 1. All the estimates of the model parameters (i.e., factor loadings, variances, co-variances of factors, etc.) were statistically significant in the model. The correlations between the three factors are not shown in the model. They were significant and strong (between .57 and .63 - these results are displayed in Table 4). For further analyses in combination to the use of the three CPTI factors, we created a total score of the CPTI, i.e., the total of all 28 items (labeled CPTI Total; $\alpha$ in the total sample $=.96$ ).

Gender and Age Comparisons As shown in Table 3, boys were found to exhibit higher mean levels than girls on the CPTI total score, as well as on the three CPTI factors. However, this difference between boys and girls was not significant concerning the GD factor. Concerning age differences, there were no significant differences between the three age groups on the total score of the CPTI. In the GD factor, there were significant differences between the age groups, with the older children being rated as exhibiting higher levels of these traits. This was the case among both boys and girls. For the CU and the INS factors, there were generally no significant age differences (with one exception: the 5-yearold girls exhibited significant lower levels of $\mathrm{CU}$ traits than the 3-year-old girls). The CPTI CU and INS scores decrease from age three to five, although not statistically significant.

External Validity of the CPTI

Criterion Validity: The CPTI factors in relation to external dimensions of interest

Zero-order and two types of partial correlations were conducted between the CPTI Total score and the three CPTI factors on one hand, and the variables of interest on the other. As expected, the 


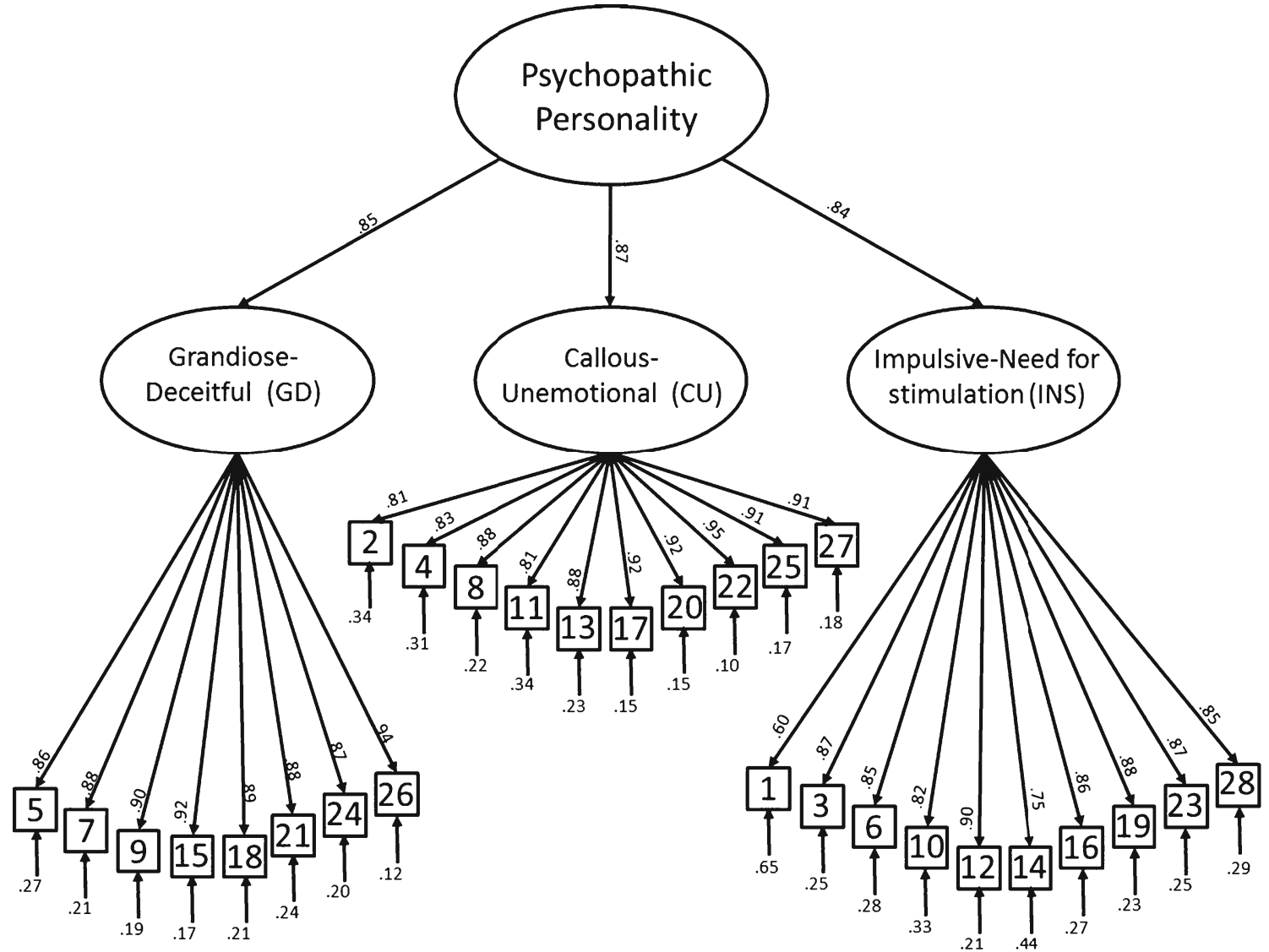

Fig. 1 Parameter estimates of three-factor model in the total sample. straight arrows from ellipses to squares represent factor loadings. straight arrows pointing at items represent residual variances. all estimates are significant

results from these analyses (displayed in Table 4) show that there were significant zero-order correlations between all the factors of the CPTI as well as the total score, with both teacher and parent rated Conduct Problems. These correlations also held and were significant when controlling for the sociodemographical variables. The correlations between the CPTI and parent rated Conduct Problems were lower than the correlations between the CPTI and teacher rated Conduct Problems.

Table 4 also shows the hypothesized positive zero order correlations between $\mathrm{CPTI}$ factors and $\mathrm{AD} / \mathrm{HD}$ symptoms and Fearlessness, and the hypothesized negative zero order correlations between CPTI factors and Easy temperament. These correlations remained significant when controlling for the socio-demographical variables.

Finally, Table 4 presents partial correlations between each CPTI factor and variables of interest after controlling for the socio-demographical variables and the other two CPTI factors (the correlations labeled Part. 2 in Table 4). As hypothesized, the partial correlations for the GD factor with teacher rated Conduct Problems was clearly lower than the zero order correlation. Between the GD factor and parent rated Conduct Problems, AD/HD symptoms, Easy temperament, and Fearlessness, these partial correlations all became zero or very close to zero. For the $\mathrm{CU}$ factor, these partial correlations with teacher- and parent rated Conduct Problems were also clearly lower than the zero order correlations, although they remained significant. Between the $\mathrm{CU}$ factor and $\mathrm{AD} / \mathrm{HD}$ symptoms, Easy temperament, and Fearlessness, these partial correlations all became clearly lower than the zero order correlations as well, but they were all still significant. For the INS factor, these partial correlations with teacher and parent rated Conduct Problems were also clearly lower than the zero order correlations, but they remained significant. Between the INS factor and $\mathrm{AD} / \mathrm{HD}$ symptoms and Fearlessness, these partial correlations all became clearly lower than the zero order correlations, but they were all still significant. Between the INS factor and Easy temperament, this partial correlation became non-significant.

Criterion Validity: The role of the individual factors and the interaction of the three CPTI factors in predicting concurrent conduct problems

With the aim to examine the role of the three CPTI factors in relation to Conduct Problems, a series of multiple regression analyses were conducted using teacher rated Conduct Problems as the dependent variable. It was expected that these analyses would prove the importance of all three CPTI factors, 


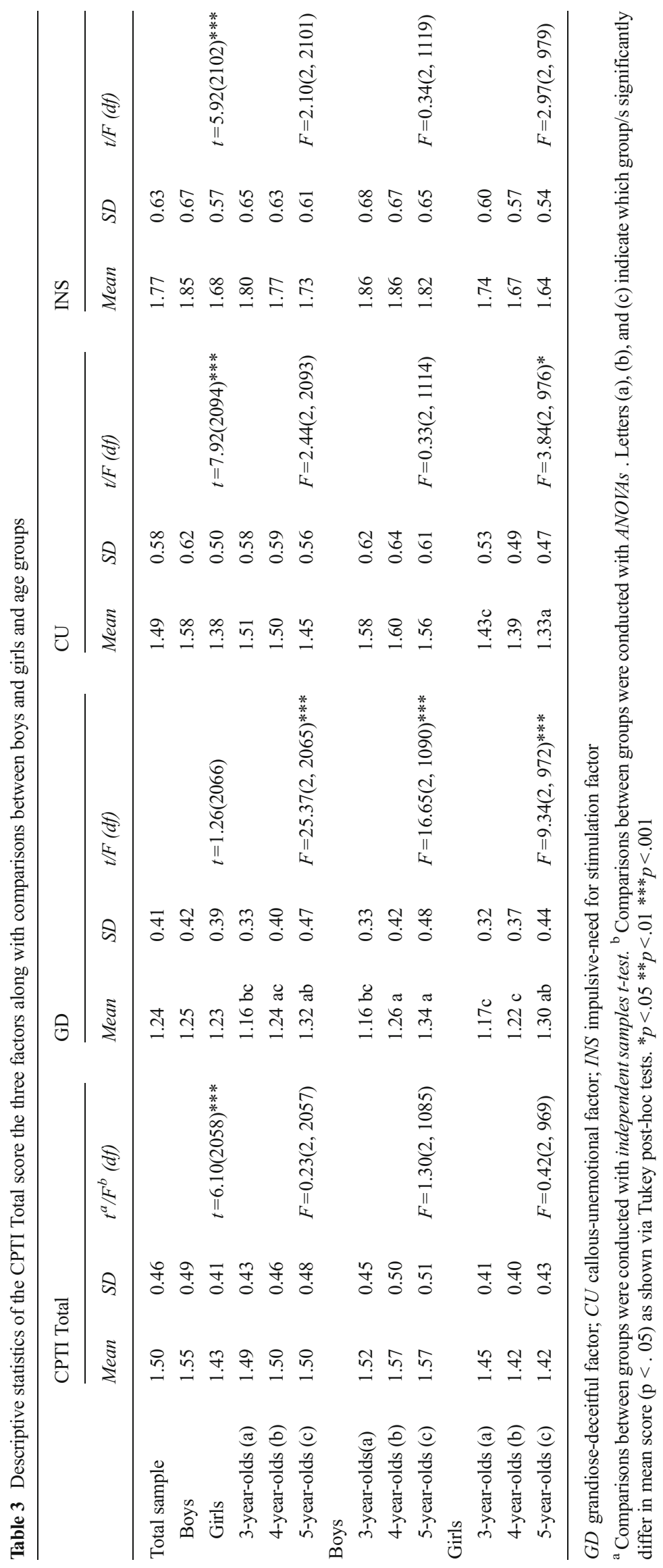


Table 4 Zero-order and partial correlations between the CPTI total score, teacher and parent rated measures of conduct problems, AD/HD and temperament

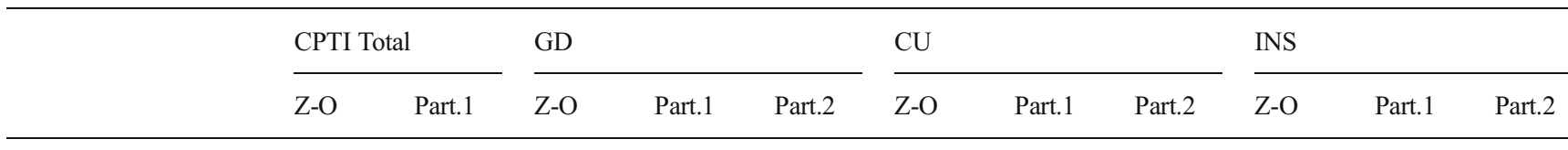

CPTI dimensions

\begin{tabular}{|c|c|c|c|c|c|c|c|c|c|c|c|}
\hline GD & $.81 * * *$ & $.81 * * *$ & & & & & & & & & \\
\hline $\mathrm{CU}$ & $.88^{* * *}$ & $.87 * * *$ & $.60 * * *$ & $.61 * * *$ & & & & & & & \\
\hline INS & $.88 * * *$ & $.88 * * *$ & $.57 * * *$ & $.59 * * *$ & & $.63 * * *$ & $.61 * * *$ & & & & \\
\hline Conduct Problems (TR) & $.76^{* * *}$ & $.76^{* * *}$ & $.58 * * *$ & $.61 * * *$ & $.24 * * *$ & $.67 * * *$ & $.65^{* * *}$ & $.30 * * *$ & $.70 * * *$ & $.68 * * *$ & $.40 * * *$ \\
\hline Conduct Problems (PR) & $.22 * * *$ & $.22 * * *$ & $.13 * * *$ & $.15^{* * *}$ & -.00 & $.20 * * *$ & $.19 * * *$ & $.07 * *$ & $.21 * * *$ & $.21 * * *$ & $.11 * * *$ \\
\hline AD/HD symptoms (TR) & $.76^{* * *}$ & $.76^{* * *}$ & $.47 * * *$ & $.49 * * *$ & $-.07 * *$ & $.60 * * *$ & $.59 * * *$ & $.20 * * *$ & $.82 * * *$ & $.82 * * *$ & $.71 * * *$ \\
\hline Easy temperament (TR) & $-.47 * * *$ & $-.45^{* * *}$ & $-.32 * * *$ & $-.33 * * *$ & -.03 & $-.54 * * *$ & $-.52 * * *$ & $-.41 * * *$ & $-.34 * * *$ & $-.30 * * *$ & .04 \\
\hline Fearlessness (TR) & $.67 * * *$ & $.67 * * *$ & $.48 * * *$ & $.49 * * *$ & $.08 * * *$ & $.58 * * *$ & $.56^{* * *}$ & $.23 * * *$ & $.65^{* * *}$ & $.64 * * *$ & $.42 * * *$ \\
\hline
\end{tabular}

$G D$ grandiose-deceitful factor; $C U$ callous-unemotional factor; INS impulsive-need for stimulation factor; $T R$ teacher rated; $P R$ parent rated; $Z-O$ zeroorder correlations; Part. $1=$ Correlations partialling out age, gender, Parent's origin and Parent's SES; Part.2=Partial correlations between one of the CPTI factors (e.g., GD) and external validity correlates, controlling for age, gender, origin, SES and the other two CPTI factors (e.g., CU and INS)

${ }^{*} p<.05 * * p<.01 * * * p<.001$

and more specifically of the combination/interaction of the three factors, in relation to Conduct Problems. That is, the interaction term of the three factors was expected to be a better predictor of Conduct Problems than any single CPTI factor. Results are presented in Table 5.

As seen in Table 5, Model 1 included only the covariates, that is the socio-demographical variables as independent variables, and showed that SES, age and gender (gender was coded as 1 for boys and 2 for girls) had weak but significant relations to Conduct Problems. Model 2 shows that the GD factor is significantly related to Conduct Problems and Model 3 shows that the model including only the $\mathrm{CU}$ factor explains more variance as compared to the model including only the
GD factor. Model 4 shows that the INS factor in fact is the best (in terms of explained variance) of the three individual CPTI factors in predicting concurrent Conduct Problems. Model 5 shows that the interaction between the three factors is better than all three individual CPTI factors in predicting Conduct Problems as indicated by the higher standardized beta and more explained variance, as compared to the models including only one CPTI factor (i.e., Models 2-4). Models 6 to 8 show that the interaction between the three CPTI factors has a unique association with Conduct Problems over and above the GD factor (Model 6), the CU factor (Model 7), and the INS factor (Model 8), and that the interaction is a stronger predictor of Conduct Problems than the GD factor (Model 6), the

Table 5 Ten different multiple regression analyses investigating main, additive, and interactive relations between socio-demographical covariates, the GD, CU and INS factors and teacher rated conduct problems

\begin{tabular}{|c|c|c|c|c|c|c|c|c|c|c|}
\hline & $\begin{array}{l}\text { Model } 1 \\
\beta\end{array}$ & $\begin{array}{l}\text { Model } 2 \\
\beta\end{array}$ & $\begin{array}{l}\text { Model } 3 \\
\beta\end{array}$ & $\begin{array}{l}\text { Model } 4 \\
\beta\end{array}$ & $\begin{array}{l}\text { Model } 5 \\
\beta\end{array}$ & $\begin{array}{l}\text { Model } 6 \\
\beta\end{array}$ & $\begin{array}{l}\text { Model } 7 \\
\beta\end{array}$ & $\begin{array}{l}\text { Model } 8 \\
\beta\end{array}$ & $\begin{array}{l}\text { Model } 9 \\
\beta\end{array}$ & $\begin{array}{l}\text { Model10 } \\
\beta\end{array}$ \\
\hline Parent's SES & $-.09 * * *$ & $-.06^{* *}$ & $-.03 *$ & $-.04 *$ & -.03 & -.03 & -.03 & -.02 & $-.03 *$ & -.02 \\
\hline Parent's origin & .02 & -.02 & -.01 & -.01 & -.02 & -.02 & -.02 & -.02 & -.03 & -.03 \\
\hline Child's age & $-.10 * * *$ & $-.20 * * *$ & $-.07 * * *$ & $-.08 * * *$ & $-.13 * * *$ & $-.13 * * *$ & $-.12 * * *$ & $-.11 * * *$ & $-.14 * * *$ & $-.11 * * *$ \\
\hline Child's gender & $-.20 * * *$ & $-.18^{* * *}$ & $-.09 * * *$ & $-.11 * * *$ & $-.11 * * *$ & $-.11 * * *$ & $-.10 * * *$ & $-.10 * * *$ & $-.11 * * *$ & $-.09 * * *$ \\
\hline GD & & $.61 * * *$ & & & & -.05 & & & $.34 * * *$ & $.21 * * *$ \\
\hline $\mathrm{CU}$ & & & $.64 * * *$ & & & & $.16^{* * *}$ & & $.44 * * *$ & $.28 * * *$ \\
\hline INS & & & & $.68 * * *$ & & & & $.30 * * *$ & & $.38 * * *$ \\
\hline GD $x$ CU x INS & & & & & $.72 * * *$ & $.76^{* * *}$ & $.59 * * *$ & $.49 * * *$ & & \\
\hline $\mathrm{R}^{2}$ & .06 & .41 & .46 & .50 & .56 & .56 & .57 & .60 & .52 & .60 \\
\hline
\end{tabular}

Teacher rated Conduct Problems is the dependent variable. $\beta$ standardized Beta. GD grandiose-deceitful factor; $C U$ callous-unemotional factor; $I N S$ impulsive-need for stimulation factor. None of the ten models had problems with multicollinearity as shown via Variance Inflation Factor (VIF) values all well below 5. A model including all variables, i.e., all socio-demographical covariates, all three CPTI factors, and the three-way interaction had problems with multicollinearity and is therefore not presented. ${ }^{*} p<.05 * * p<.01 * * * p<.001$ 
CU factor (Model 7), or the INS factor (Model 8) on their own. A plot of this three-way interaction (i.e., between the three CPTI factors while taking into account all the combinations of two-way interactions between the CPTI factors) clearly showed that high levels on all three factors, was associated with the highest level of Conduct Problems, as compared to all other possible constellations/interactions of the three factors. Models 9 and 10 show that there are some minor additive effects of the three factors in relation to Conduct Problems, as adding a factor increases the explained variance, albeit not much. A model including all variables (i.e., socio-demographical covariates, three CPTI factors, and the three-way interaction had problems with multicollinearity and is therefore not presented.

\section{Discussion}

\section{Summary of the Main Findings}

Little is known about when psychopathic traits develop and how early in life they can be detected and measured in a meaningful way. To fill this void, the present study presented a new instrument (i.e., the CPTI) to assess traits applicable to children in line with the three-factor conceptualization of psychopathic personality. The CPTI exhibits good internal, factorial validity, consisting of three distinct but interrelated factors. This three factor model fitted the data well among boys and girls and in the various age groups, and clearly better than a one-factor model of all items in the CPTI and a Callousunemotional (CU) factor model consisting of the $\mathrm{CU}$ items only. In addition, the three factors and the total score showed excellent internal consistency in the total group as well as across gender and all three age groups. As hypothesized, boys had higher CPTI factor scores than girls, although this gender difference was not significant for the Grandiose-Deceitful (GD) factor. In general, there were no significant age differences in the CU and Impulsive-Need for Stimulation (INS) factors, although older children showed significantly higher levels of the GD factor. In terms of external validity, the three factors exhibited the hypothesized zero-order correlations with Conduct Problems, AD/HD symptoms, Easy temperament, and Fearlessness. Importantly, these correlations remained significant but decreased in strength when controlling for the other two CPTI factors. This confirms our hypothesis that the factors at least in part depend on each other in their relation to these external dimensions. In fact, the present study showed that the GD factor in itself, without the other two factors, did not exhibit meaningful correlations with these external variables (most were zero or close to zero). Finally, and as hypothesized, the interaction between the three CPTI factors was shown to be the strongest predictor of concurrent Conduct Problems, stronger than any of the three CPTI factors on their own. This latter finding, together with better model fit of the three-factor model than the CU factor only model, underlines the utility of assessing not only the CU factor, but also the other two factors of the psychopathic personality.

\section{The Novelty of the Present Study}

Some studies have supported the existence and measurement of psychopathic traits in children (Cornell and Frick 2007; Johnstone and Cooke 2004; Kimonis et al. 2006). Most of them have focused on traits related to the CU dimension (Dadds et al. 2005; Rowe et al. 2010), and have used measures of psychopathic traits originally created for use in school-aged children and adolescents samples (i.e., APSD, ICU). The CPTI is the first instrument originally developed and validated with the aim to assess the three-factor model conceptualization of psychopathic personality from early childhood.

The Present Findings in Relation to Previous Research

Several previous studies have shown that the correlation between the interpersonal and affective (or $\mathrm{CU}$ ) dimensions of the psychopathic personality and conduct problems tends to decrease, or even disappear when controlling for the behavioral dimension (e.g., Colledge and Blair 2004; Frick et al. 2005). This study showed that the relation between the GD factor and Conduct Problems largely disappeared when controlling for the other two CPTI factors. However, the CPTI CU factor was still significantly correlated with Conduct Problems when controlling for the other two factors. This discrepancy may be explained by the differences the instruments used. That is, these measures (e.g., APSD, YPI) have been developed from the classic conceptualization of psychopathic personality (Kotler and McMahon 2010), and therefore includes rule-breaking, antisocial behavior and irresponsibility in the behavioral dimension. This implicates that the behavioral dimension of these instruments overlap with measures that assess conduct problems. One of the main guiding principles was to develop the CPTI with as little contamination or overlap as possible with conduct problems, antisocial, and criminal behaviors. This was considered important and fundamental because the CPTI is aimed at measuring something that can be used to at least partly explain and predict severe conduct problems and other antisocial behaviors. Thus, the CPTI excludes irresponsibility and conduct problems because these two are some of the most important outcomes that the instrument aims to explain and predict. In summary, this may explain why CU traits as measured by the CPTI clearly remained significantly related to conduct problems, even when controlling for the other two factors of the CPTI.

The current results also converge with previous studies that repeatedly proposed fearlessness and temperamental difficulties to be central temperamental features underlying the development 
of the psychopathic personality and its traits (Frick et al. 2003; Lykken 1995; Lynam 1997b). In the present study, zero order correlations showed that all three CPTI factors were negatively related to easy temperament, and positively related to fearlessness. Yet, after controlling for the other CPTI factors, the CPTI GD and INS factors were close to zero related to easy temperament, while the GD factor also had a close to zero correlation to fearlessness. The CPTI CU factor remained almost equally strong related with easy temperament but less strongly though still significantly related to fearlessness. This pattern of findings suggests that to understand how each dimension of the psychopathic personality relates to easy temperament and fearlessness, all three dimensions should be considered together, not in isolation from each other.

Most of the studies mentioned so far, have highlighted the role of CU traits as the most important dimension of psychopathic personality (White and Frick 2010) as evidenced by their concurrent and prospective relation to conduct problems, aggression and delinquency (e.g., McMahon et al. 2010). CU traits have also showed their utility in identifying a subgroup of children who develop early onset conduct problems (Frick 2009), and the most severe and persistent pattern of future antisocial behavior and psychosocial disorders (Rowe et al. 2010; but see Colins and Vermeiren 2013). Therefore, CU traits have been suggested as a classification criterion for Conduct Disorder in the DSM-5 (Frick and Moffitt 2010). However, if we consider the threedimensional structure of psychopathic personality, based on the jointly presence of interpersonal, affective and behavioral traits using the $\mathrm{CU}$ dimension alone might be not be the best solution when, for example, predicting conduct problems. Indeed, results of the present study showed a substantial interactional effect of the three CPTI factors in relation to conduct problems. The results also showed that the presence of all three dimensions was a stronger predictor of concurrent conduct problems than CU traits alone or INS alone (cf. Lynam's theory). This suggests that future studies need to be open for that it may be the case that the use of all dimensions of the psychopathic personality construct is a better way of assessing psychopathic personality in children, and that this may be a better way to predict conduct problems. Longitudinal studies are needed to investigate this further.

\section{Use of Teacher Ratings}

We specifically developed the CPTI to be primarily rated by teachers. This decision must be explained against earlier recommendations to use multiple sources of information in the study of child and adolescent psychopathic personality (Vitacco et al. 2010). Even though our intention was not to exclude the possibility for the CPTI to be used by parents, we here present four reasons for why we argue teachers should be the first informant of choice when assessing psychopathic traits in children.
First, given that most parents of young children have a job, their children actually spend more time with their teacher. Therefore, teachers have the opportunity to see children in many more different situations (e.g., free play, structured activities) and interacting with many different people (e.g., peers, older and younger children) for a longer period of time (see also Abikoff et al. 1993). Second, as a consequence of their education and/or experience, teachers may better distinguish between age-related normative and age-related inappropriate traits and behaviors (e.g., Campbell 2002) than parents. Third, the content of most of the items assessed in a measure that taps psychopathic traits have a negative connotation. Because parents can be assumed to be more emotionally involved with their children than teachers, they may be unwilling to report negative features of their child or minimalize the frequency or severity of these features. Fourth, all studies that relied on teachers to assess psychopathic traits in early childhood (Ezpeleta et al. 2013; Scholte et al. 2011) reported better internal consistency indices for the dimensions of psychopathic personality than studies that relied on parent reports (Dadds et al. 2005; Scholte and van der Ploeg 2007; Waller et al. 2012; Willoughby et al. 2012).

\section{Strengths and Limitations of the Present Study}

The major strength of the current study is that the CPTI has been validated in a large representative sample of children, with low attrition between the target population and the final sample, and no relevant differences with non-participating children on key variables (see the Method section). Another strength is that the sample size enabled us to present results for gender and age groups, two issues that have received considerable and increasing attention in the literature (e.g., Colins et al. 2012; Sevecke and Kosson 2010). The major limitation is the cross-sectional design of the study, which does not allow testing of the predictive power of psychopathic personality to future conduct problems. The CPTI has been validated in a large sample here but with a restricted age range ( 3 to 5 years), providing no support for the reliability and validity of the CPTI in older children. Another limitation was the use of several previously untested measures. The measure of $\mathrm{AD} /$ HD symptoms was a previously published and validated scale but the other scales were not. Thus, their validity is uncertain, although we would argue that they have high face validity and they do correlate in expected ways with psychopathic personality traits (see Table 4). Finally, we did not collect parentrated CPTI data, meaning that we cannot empirically test our rationale to use teachers as primary raters.

\section{Future Research Directions}

To test the generalizability of the current finding to other samples of community youth and clinic-referred youth, future studies are 
needed to test the CPTIs factor structure, reliability and external validity in 3- to 12-year-old children. Relatively little crosscultural research exists on the functioning of psychopathy instruments in children and adolescents (Verona et al. 2010). Therefore, future studies that test the psychometric properties of the CPTI in different countries, cultures and/or ethnic groups are particularly important. If, for example, the factor structure of the CPTI, and its relation to variables of interest, can be replicated across countries and cultures, confidence that the CPTI consistently and validly assesses an early manifestation of psychopathic personality will increase.

Having a reliable and well-validated instrument available that taps psychopathic personality traits in early childhood will help answering the intriguing question of how many children with high levels of psychopathic traits will become our tomorrow's adult psychopaths. Describing and understanding the so called ipsative stability and change of the psychopathic personality is key because this approach would test the stability and change of the various constellations across the three psychopathic personality factors (see Andershed 2010). Also, understanding why there is stability and change, is key in understanding the development of psychopathic personality from childhood to adulthood (e.g., Salekin 2010).

In addition, the CPTI will also allow to test and inform competing developmental theories to understand the development of serious antisocial behavior in general and the psychopathic personality in specific. A hypothesis is that psychopathic personality in early childhood (i.e., being high on all three factors) is a better predictor of conduct problems in childhood and psychopathy in adulthood, than one dimension on its own (e.g., CU traits). Testing this hypothesis in different samples and settings is relevant given that only the $\mathrm{CU}$ dimension is in the DSM-5 to identify a severe group of children with CD.

Further validation of the CPTI should also relate on other methods than teacher report, such as natural observations, laboratory tests, and/or neurobiological measures. Many innovative techniques are being used to increase our understanding of psychopathic personality. Yet, a basic issue that needs ongoing and thorough attention is assessment of this personality (Salekin 2010). Therefore, it will be important for future studies to relate the CPTI to other existing measures of psychopathic traits in children (e.g., APSD, YPI-Child Version). Likewise, it will be relevant to compare the CPTI with existing instruments in, for example, predictive utility of conduct problems and antisocial behavior, specifically because the CPTI in contrast to these other measures show no overlap with these latter two constructs.

Finally, being able to measure psychopathic traits in early childhood will also enable the further validation of differentiating between primary and secondary variants of psychopathy (e.g., Kimonis et al. 2012; Lee and Salekin 2010; Skeem et al. 2007). Secondary variants are hypothesized to acquire psychopathy as a consequence of negative environmental influences early in life (e.g., maltreatment), and primary variants mainly as a consequence of genetic vulnerabilities (Skeem and Cauffman 2003). Longitudinal studies that use measures to assess both psychopathic traits and trauma exposure will enable to examine pathways that may lead to primary and secondary psychopathy, an issue that has not yet been tested in such studies.

Ethical Considerations with the Extension of the Psychopathic Personality Construct to Childhood

When studies started to extend the adult psychopathy construct downwards to children and adolescents, a concern was raised that this pejorative label would be stigmatizing and negatively affect the perception of these children from mental health professionals and juvenile justice personnel. Mental health services may be less willing to start an intervention or treatment program with an adolescent labeled with the term psychopathic personality, while juvenile judges may impede harsher sentences when dealing with a so called fledgling psychopath. Indeed, it is easy to put a label in a file that unintentionally may follow the child or adolescent for the rest of his or her life. Yet, the same can be said about other, more accepted constructs in clinical work and justice proceedings, such as CD. Interestingly, there is some evidence that the term "child psychopathy" does not differ much from Conduct Disorder in terms of court personnel's perceptions (Murrie et al. 2007). Having said this, concerns will probably and should rise again now that researchers try to extend the construct of adult psychopathy even further downwards to early childhood.

Regarding the importance of exploring the psychopathic personality construct in early childhood from a clinical perspective, we want to emphasize that the construct of psychopathic personality should not yet be used in clinical practice with preschool children. The use of the psychopathic personality construct may be clinically useful the day there is confidence that we would not carry out needless interventions in the life of too many children. Several researchers, including the authors of the current paper, are reluctant to use the psychopathic personality construct in early childhood in clinical practice. These concerns do not only relate to possibilities to measure this construct reliably and validly in infants and young children, but also to the lack of stability in studies that span different developmental periods in life (e.g., Skeem et al. 2011).

\section{General Conclusion}

To better understand the developmental precursors of psychopathic personality and severe conduct problems, it is crucial to try and assess these traits early in life. Therefore, the development and validation of the CPTI is a first vital step into a new research field regarding early child development of the psychopathic personality, its risk factors, and its stability and change over time. Findings from the present study are promising as the CPTI seems 
capable of capturing the three-factor conceptualization of the psychopathic personality in 3- to 5-year-old children in a way that very much goes in line with how these traits are conceptualized and assessed in late childhood (e.g., van Baardewijk et al. 2008), adolescence (e.g., Andershed et al. 2002) and young adulthood (e.g., Cooke and Michie 2001; Neumann and Pardini 2012).

Acknowledgment Henrik Andershed was financed by funds for the Swedish Research Council during the preparation of this manuscript and the SOFIA study was also financed by the Swedish Research Council. We are grateful to Karlstad University and Karlstad municipality for their collaboration in the SOFIA study.

Open Access This article is distributed under the terms of the Creative Commons Attribution License which permits any use, distribution, and reproduction in any medium, provided the original author(s) and the source are credited.

\section{References}

Abikoff, H., Courtney, M., Pelham, W. E. J., \& Koplewicz, H. S. (1993). Teacher's Ratings of disruptive behaviors: the influence of halo effects. Journal of Abnormal Child Psychology, 21, 519-533.

Andershed, H. (2010). Stability and change of psychopathic traits. What do we know? In R. T. Salekin \& D. R. Lynam (Eds.), Handbook of child and adolescent psychopathy (pp. 233-250). New York: The Guilford Press.

Andershed, H., Kerr, M., Stattin, H., \& Levander, S. (2002). Psychopathic traits in non-referred youths: A new assessment tool. In E. Blaauw \& L. Sheridan (Eds.), Psychopaths: Current international perspectives (pp. 131-158). The Hague: Elsevier.

Andershed, H., Köhler, D., Louden, J. E., \& Hinrichs, G. (2008). Does the three-factor model of psychopathy identify a problematic subgroup of young offenders? International Journal of Law and Psychiatry, 31, 189-198

APA. (2000). Diagnostic and statistical manual of mental disorders (4th ed.). Washington DC: American Psychiatric Association.

Bandstra, N. F., Chambers, C. T., McGrath, P. J., \& Moore, C. (2011). The behavioural expression of empathy to others' pain versus others' sadness in young children. Pain, 152(1074-1082).

Bigelow, A. E., \& Dugas, K. (2008). Relations among preschool children's understanding of visual perspective taking, false belief, and lying. Journal of Cognition and Development and Psychopathology, 9(4), 411-433.

Browne, M. W., \& Cudeck, R. (1993). Alternative ways of assessing model fit. In K. A. Bollen \& J. S. Long (Eds.), Testing structural equation models (pp. 136-162). Beverly Hills: Sage.

Campbell, S. B. (2002). Behavior problems in preschool children. Clinical and developmental issues (2nd ed.). New York: The Guilford Press.

Carlson, S. M. (2005). Developmentally sensitive measures of executive function in preschool children. Developmental Neuropsychology, $28,595-616$.

Carlson, K. S., \& Gjerde, P. F. (2009). Preschool personality antecedents of narcissism in adolescence and young adulthood: a 20-year longitudinal study. Journal of Research in Personality, 43, $570-578$

Chacko, A., Wakschlag, L., Hill, C., Danis, B., \& Espy, K. A. (2009). Viewing preschool disruptive behavior disorders and attentiondeficit/hyperactivity disorder through a developmental lens: what we know and what we need to know. Child and Adolescent Psychiatric Clinics of North America, 18, 627-643.

Christian, R. E., Frick, P. J., Hill, N. L., Tyler, L., \& Frazer, D. L. (1997). Psychopathy and conduct problems in children: II. Implications for subtyping children with conduct problems. Journal of the American Academy of Child and Adolescent Psychiatry, 36, 233-241.

Cohen, J. (1988). Statistical power analysis for the behavioral sciences (2nd ed.). Hillsdale: Erlbaum.

Colins, O. F., \& Vermeiren, R. (2013). The usefulness of DSM-IV and DSM-5 conduct disorder subtyping in detained adolescents. Journal of Nervous and Mental Disease, 201 (9), 736-43. doi:10.1097/ NMD.0b013e3182a20e94.

Colins, O., Noom, M., \& Vanderplasschen, W. (2012). Youth psychopathic traits inventory - short version: a further test of the internal consistency and criterion validity. Journal of Psychopathology and Behavioral Assessment, 34(4), 476-486.

Colledge, E., \& Blair, R. J. R. (2004). The relationship in children between the inattention and impulsivity components of attention deficit and hyperactivity disorder and psychopathic tendencies. Personality and Individual Differences, 30, 1175-1187.

Cooke, D. J., \& Michie, C. (2001). Refining the construct of psychopathy: towards a hierarchical model. Psychological Assessment, 13, 171-188.

Cornell, A. H., \& Frick, P. J. (2007). The moderating effects of parenting styles in the association between behavioral inhibition and parentreported guilt and empathy in preschool children. Journal of Clinical Child and Adolescent Psychology, 36, 305-318.

Cramer, P. (2011). Young adult narcissism: a 20 year longitudinal study of the contribution of parenting styles, preschool precursors of narcissism, and denial. Journal of Research in Personality, 45, 19-28.

Dadds, M. R., Fraser, J., Frost, A., \& Hawes, D. J. (2005). Disentangling the underlying dimensions of psychopathy and conduct problems in childhood: a community study. Journal of Consulting and Clinical Psychology., 73, 400-410.

Decety, J., Michalska, K. J., Akitsuki, Y., \& Lahey, B. B. (2009). Atypical empathic responses in adolescents with aggressive conduct disorder: a functional MRI investigation. Biological Psychology, 90, 203-211

Depaulo, B. M., \& Kashy, D. A. (1998). Everyday lies in close and casual relationships. Journal of Personality and Social Psychology, 74, 63-79.

Dowsett, S. M., \& Livesey, D. J. (2000). The development of inhibitory control in preschool children: effects of "executive skills" training. Developmental Psychobiology, 36(161-174).

DuPaul, G. J., Power, T. J., Anastopoulos, A. D., \& Reid, R. (1998). ADHD rating scale-IV: Checklists, norms, and clinical interpretation. New York: The Guilford Press.

Eggers, H. L., \& Angold, A. (2006). Common emotional and behavioral disorders in preschool children: presentation, nosology, and epidemiology. Journal of Child Psychology and Psychiatry, 47(3), 313-337.

Eisenberg, N. (2000). Emotion, regulation and moral development. Annual Review of Psychology, 51, 665-697.

Essau, C. A., Sasagawa, S., \& Frick, P. J. (2006). Callous-unemotional traits in a community sample of adolescents. Assessment, 13(454 469).

Ezpeleta, L., de La Osa, N., Granero, R., Penolo, E., \& Domenech, J. M. (2013). Inventory of callous-unemotional traits in a community sample of preschoolers. Journal of Clinical Child \& Adolescent Psychology, 22(1), 91-105.

Flora, D. B., \& Curran, J. P. (2004). An empirical evaluation of alternative methods of estimation for confirmatory factor analysis with ordinal data. Psychological Methods, 4, 466-491.

Frick, P. J. (2009). Extending the construct of psychopathy to youth: implications for understanding, diagnosing, and treating antisocial children and adolescents. The Canadian journal of Psychiatry, 54(12), 803-812.

Frick, P. J., \& Dickens, C. A. (2006). Current perspectives on conduct disorder. Current Psychiatry Reports, 8, 59-72. 
Frick, P. J., \& Hare, R. D. (2001). The antisocial process screening device. Toronto: Multi-Health Systems.

Frick, P. J., \& Moffitt, T. E. (2010). A proposal to the DSM-V childhood disorders and the ADHD and disruptive behavior disorders work groups to include a specifier to the diagnosis of conduct disorder based on the presence of callous-unemotional traits. Washington, D.C.: American Psychiatric Association.

Frick, P. J., \& Viding, E. (2009). Antisocial behavior from a developmental psychopathology perspective. Development and Psychopathology, 21, $1111-1131$

Frick, P. J., \& White, S. F. (2008). Research review: the importance of callous-unemotional traits for developmental models of aggressive and antisocial behavior. The Journal of Child Psychology and Psychiatry., 49(4), 359-375.

Frick, P. J., Bodin, D. S., \& Barry, C. T. (2000). Psychopathic traits and conduct problems in community and clinic-referred samples of children: further development of the psychopathy screening device. Psychological Assessment, 12, 382-393.

Frick, P. J., Cornell, A. H., Bodin, D. S., Dane, H. E., Barry, C. T., \& Loney, B. R. (2003). Callous-unemotional traits and developmental pathways to severe conduct problems. Developmental Psychology, 39, 246-260.

Frick, P. J., Stickle, T. R., Dandreaux, D. M., Farrell, J. M., \& Kimonis, E. R. (2005). Callous-unemotional traits in predicting the severity and stability of conduct problems and delinquency. Journal of Abnormal Child Psychology, 33, 471-487.

Fu, G., Evans, D. E., Xu, F., \& Lee, K. (2012). Young children can tell strategic lies after committing a transgression. Journal of Experimental Child Psychology, 113, 147-158.

Garon, N., Bryson, S. E., \& Smith, I. M. (2008). Executive function in preschoolers: a review using an integrative framework. Psychological Bulletin, 134(1), 31-60.

Hala, S., Chandler, M., \& Fritz, A. S. (1991). Fledgling theories of mind: deception as a marker of three-year-olds' understanding of false belief. Child Development, 62, 83-97.

Hare, R. D. (2003). Manual for the revised psychopathy checklist (2nd ed.). Toronto: Multi-Health Systems.

Hart, S. D., \& Hare, R. D. (1998). Association between psychopathy and narcissism: Theoretical views and empirical evidence. In E. Ronningstam (Ed.), Disorders of narcissism: Theoretical, empirical, and clinical implications. Washington: American Psychiatric Press.

Hu, L., \& Bentler, P. M. (1999). Cutoff criteria for fit indexes in covariance structure analysis: conventional criteria versus new alternatives. Structural Equation Modeling, 6, 1-55.

Johnstone, L., \& Cooke, D. J. (2004). Psychopathic-like traits in childhood: conceptual and measurement concerns. Behavioral Sciences and the Law, 22, 103-125.

Jones, A. P., Happé, F. G. E., Gilbert, F., Burnett, S., \& Viding, E. (2010). Feeling, caring, knowing: different types of empathy deficit in boys with psychopathic tendencies and autism spectrum disorder. Journal of Child Psychology and Psychiatry, 51 (11), 1188-1197.

Kimonis, E. R., Frick, P. J., Boris, N. W., Smyke, A. T., Cornell, A. H., Farrel, J. M., et al. (2006). Callous-unemotional features, behavioral inhibition, and parenting: independent predictors of aggression in a high-risk preschool sample. Journal of Child and Family Studies, $15,745-756$.

Kimonis, E. R., Frick, P. J., Cauffman, E., Goldweber, A., \& Skeem, J. L. (2012). Primary and secondary variants of juvenile psychopathy differ in emotional processing. Development and Psychopathology, 24, 1091-1103.

Kline, R. B. (2011). Principles and practice of structural equation modeling. New York: The Guilford Press.

Knafo, A., Zahn-Waxler, C., Davidov, M., van Hulle, C., Robinson, J., \& Rhee, S. Y. (2009). Empathy in early childhood: genetic, environmental, and affective contributions. Values, Empathy, and Fairness across Social Barriers, 1167, 103-114.
Koshanska, G., \& Aksan, N. (2006). Children's conscience and selfregulation. Journal of Personality, 74(6), 1587-1618.

Koshanska, G., De Vet, K., Goldman, M., \& Murray, K. (1994). Maternal reports of conscience development and temperament in young children. Child Development, 65(3), 852-868.

Koshanska, G., Murray, K., Jacques, T. Y., Koenig, A. L., \& Vandegeest, K. A. (1996). Inhibitory control in young children and its role in emerging internalization. Child Development, 67, 420-507.

Koshanska, G., Murray, K., \& Harlan, E. T. (2000). Effortful control in early childhood: continuity and change, antecedents and implications for social development. Developmental Psychology, 36, 220-232.

Koshanska, G., Gross, J. N., Lin, M. H., \& Nichols, K. E. (2002). Guilt in young children: development, determinants, and relations with a broader system of standards. Child Development, 73(2), 461-482.

Kotler, J. S., \& McMahon, R. J. (2010). Assessment of child and adolescent psychopathy. In R. T. Salekin \& D. R. Lynam (Eds.), Handbook of child and adolescent psychopathy. New York: The Guilford Press.

Lee, K. (2000). The development of lying: How children do deceptive things with words. In J. W. Astington (Ed.), Minds in making. Oxford, Engeland: Blackwell.

Lee, Z., \& Salekin, R. T. (2010). Psychopathic traits in youth: is there evidence for primary and secondary subtypes? Journal of Abnormal Child Psychology, 38, 381-393.

Lee, Z., Klaver, J. R., \& Hart, S. D. (2008). Psychopathy and verbal indicators of deception in offenders. Psychology, Crime \& Law, 14(1), 73-84.

Lewis, M., Stanger, C., \& Sullivan, M. W. (1989). Deception in 3-yearolds. Developmental Psychology, 25(3), 439-443.

Lykken, D. T. (1995). The antisocial personalities. Hillsdale: Lawrence Erlbaum.

Lynam, D. R. (1996). Early identification of chronic offenders: who is the fledgling psychopath? Psychological Bulletin, 120(2), 209-234.

Lynam, D. R. (1997a). Pursuing the psychopath: capturing the fledgling psychopath in a nomological net. Journal of Abnormal Psychology, 106(3), 425-438.

Lynam, D. R. (1997b). Pursuing the psychopath: capturing the fledgling psychopath in a nomological net. Journal of Abnormal Psychology, 106, 425-438.

Lynam, D. R., Miller, D. J., Vachon, D., Loeber, R., \& StouthamerLoeber, M. (2009). Psychopathy in adolescence predicts official reports of offending in adulthood. Youth Violence and Juvenile Justice, 7, 189-207.

McDonald, N. M., \& Messinger, D. S. (2009). The development of empathy: how, when, and why Retrieved december 2012

McMahon, R. J., Witkiewitz, K., \& Kotler, J. S. (2010). Predictive validity of callous-unemotional traits measured in early adolescence with respect to multiple antisocial outcomes. Journal of Abnormal Psychology, 119, 752-763.

Morrongiello, B. A., \& Lasenby, J. (2006). Finding the daredevils: development of a sensation seeking scale for children that is relevant to physical risk taking. Accident Analysis and Prevention, 38(1101-1106).

Morrongiello, B. A., Sandomierski, M., \& Vall, J. (2012). Early identification of children at risk of unintentional injury: a sensation seeking scale for children 2-5 years of age. Accident Analysis and Prevention, $42,1332-1337$.

Murrie, D. C., Boccacini, M. T., McCoy, W., \& Cornell, D. G. (2007). Diagnostic labelling in juvenile court: how do psychopathy and conduct disorder findings infuence judges? Journal of Clinical Child \& Adolescent Psychology, 36, 228-241.

Muthén, L. K., \& Muthén, B. O. (2011). Mplus (6.12) [Computer software]. Retrieved from http://www.statmodel.com/programs. shtml.

Neumann, C. S., \& Pardini, D. (2012). Factor structure and construct validity of the Self-Report Psychopathy (SRP) scale and the Youth Psychopathic Traits inventory (YPI) in young men. Journal of Personality Disorders. doi:10.1521/pedi_2012_26_063. 
Neumann, C. S., Hare, R. D., \& Newman, J. P. (2007). The super-ordinate nature of the psychopathy checklist-revised. Journal of Personality Disorders, 21(2), 102-117.

Pardini, D. (2006). The callousness pathway to severe violent delinquency. Aggressive Behavior, 32, 590-598.

Pollak, A., \& Harris, P. L. (1999). Deception by young children following noncompliance. Developmental Psychology, 29, 74-87.

Ponitz, C. C., McClelland, M. M., Mathews, J. S., \& Morrison, F. J. (2009). A structured observation of behavioral self-regulation and its contribution to kindergarten outcomes. Developmental Psychology, 45(3), 605-619.

Rowe, R., Maughan, B., Moran, P., \& Ford, T. (2010). The role of callous and unemotional traits in the diagnosis of conduct disorder. Journal of Child Psychology and Psychiatry, 51 (6), 688-695.

Salekin, R. T. (2008). Psychopathy and recidivism from midadolescence to young adulthood: cumulating legal problems and limiting life opportunities. Journal of Abnormal Psychology, 17(2), 386-395.

Salekin, R. T. (2010). Treatment of child and adolescent psychopathy: Focusing on change. In R. T. Salekin \& D. R. Lynam (Eds.), Handbook of child and adolescent psychopathy (pp. 343-373). New York: The Guilford Press.

Salekin, R. T., \& Lynam, D. R. (2010). Handbook of Child and Adolescent Psychopathy New York: The Guilford Press.

Sandseter, E. B. H., \& Kennair, L. E. O. (2012). Children's risky play from an evolutionary perspective: the anti-phobic effects of thrilling experiences. Evolutionary Psychology, 9(2), 257-284.

Scholte, E., \& van der Ploeg, J. (2007). The development of a rating scale to screen social and emotional detachment in children and adolescents. International Journal of Methods in Psychiatric Research, 16(3), 137-149.

Scholte, E., Stoutjesdijk, R., Van Oudheusden, M. A. G., Lodewijks, H., \& Van der Ploeg, J. (2011). Screening of egocentric and unemotional characteristics in incarcerated and community children. International Journal of Law and Psychiatry, 33, 164-170.

Schumacker, R. S., \& Lomax, R. G. (2004). A beginner's guide to structural equation modeling. Mahwah: Lawrence Erlbaum Associates.

Seals, W. R., Sharp, C., Ha, C., \& Michonski, J. D. (2012). The relationship between the youth psychopathic traits inventory and psychopathology in a U.S. Community sample of male youth. Journal of Personality Assessment, 94(3), 232-243.

Sevecke, K., \& Kosson, D. S. (2010). Relationships of child and adolescent psychopathy to other forms of psychopathology. In R. T. Salekin \& D. R. Lynam (Eds.), Handbook of child and adolescent psychopathy. New York: The Guilford Press.

Shamay-Tsoory, S. G., Aharon-Peretz, J., \& Perry, D. (2009). Two systems for empathy: a double dissociation between emotional and cognitive empathy in inferior frontal gyrus versus ventromedial prefrontal lesions. Brain, 132, 617-627.

Shirtcliff, E. A., Vitacco, M. J., Graf, A. R., Gostisha, A. J., Merz, J. L., \& Zahn-Waxler, C. (2009). Neurobiology of empathy and callousness: implications for the development of antisocial behavior. Behavioral Sciences and the Law, 27, 137-171.

Singer, T. (2006). The neuronal basis and ontogeny of empathy and mind reading: review of literature and implications for future research. Neuroscience and Biobehavioral Reviews, 30, 855-863.

Skeem, J. L., \& Cauffman, E. (2003). Views of the downward extension: comparing the youth version of the psychopathy checklist with the youth psychopathic traits inventory. Behavioral Sciences \& the Law, $21(6), 737-770$.

Skeem, J. L., Johansson, P., Andershed, H., Kerr, M., \& Louden, J. E. (2007). Two subtypes of psychopathic violent offenders that parallel primary and secondary variants. Journal of Abnormal Psycholog, $116(2), 395-409$
Skeem, J. L., Polaschek, D. L. L., Partrick, C. J., \& Lilienfeld, S. O. (2011). Psychopathic personality: bridging the gap between scientific evidence and public policy. Psychological Science in the Public Interest, 12(3), 95-162.

Steiger, J. M. (1990). Structural model evaluation and modification: an interval estimation approach. Multivariate Behavioral Research, 25, 173-180.

Stouthamer-Loeber, M. (1986). Lying as a problem behavour in children: a review. Clinical Psychology Review, 6, 267-289.

Talwar, V., \& Lee, K. (2008). Social and cognitive correlates of children's lying behavior. Child Development, 79(4), 866-881.

Thomaes, S., Bushman, B., Orobrio De Castro, B., \& Stegge, H. (2009). What makes narcissists bloom? A framework for research on the etiology and development of narcissism. Development and Psychopathology, 21, 1233-1247.

Tilghman-Osborne, C., Cole, D. A., \& Felton, J. W. (2010). Definition and measurement of guilt: implications for clinical research and practice. Clinical Psychology Review, 30, 536-546.

van Baardewijk, Y., Stegge, H., Andershed, H., Thomaes, S., Scholte, E., \& Vermeiren, R. (2008). Measuring psychopathic traits in children through self-report. The development of the youth psychopathic traits inventory-child version. [Article]. International Journal of Law and Psychiatry, 31(3), 199-209. doi:10.1016/j.ijlp.2008.04.004.

Verona, E., Sadeh, N., \& Javadni, S. (2010). The influences of gender and culture on child and adolescent psychopath. In R. T. Salekin \& D. R. Lynam (Eds.), Handbook of Child and Adolescent Psychopathy (pp. 317-342). New York: The Guilford Press.

Vincent, G. M., Vitacco, M. J., Grisso, T., \& Corrado, R. R. (2003). Subtypes of adolescent offenders: affective traits and antisocial behavior patterns. Behavioral Sciences \& the Law, 21(6), 695-712.

Vitacco, M. J., \& Kosson, D. S. (2010). Understanding psychopathy through an evaluation of interpersonal behavior: testing the factor structure of the interpersonal measure of psychopathy in a large sample of jail detainees. Psychological Assessment, 22 (3), 638-649.

Vitacco, M. J., Salekin, R. T., \& Rogers, R. (2010). Forensic issues for child and adolescent psychiatry. In R. T. Salekin \& D. R. Lynam (Eds.), Handbook of child and adolescent psychopathy. New York: The Guilford Press.

Waller, R., Gardner, F., Hyde, L. W., Shaw, D. S., Dishion, T. J., \& Wilson, M. N. (2012). Do harsh and positive parenting predict parent reports of deceitful-callous behavior in early childhood? Journal of Child Psychology and Psychiatry, 53(9), 946-953.

Walter, H. (2012). Social cognitive neuroscience of empathy: concepts, circuits, and genes. Emotion Review, 4(1), 9-17.

West, S. G., Finch, J. F., \& Curran, J. P. (1995). Structural equation models with non-normal variables: Problems and remedies. In R. H. Hoyle (Ed.), Structural equation modeling: Concept, issues and applications (pp. 56-67). Thousand Oaks: Sage Publishing.

White, S. F., \& Frick, P. J. (2010). Callous-unemotional traits and their importance to causal models of severe antisocial behavior in youth. In R. T. Salekin \& D. R. Lynam (Eds.), Handbook of child and adolescent psychopathy (pp. 135-155). New york: The Guilford Press.

Willoughby, M., Waschbusch, D., Moore, G., \& Propper, C. (2011). Using the ASEBA to screen for callous unemotional traits in early childhood: factor structure, temporal stability, and utility. Journal of Psychopathology and Behavioral Assessment, 33(19-30).

Willoughby, M. T., Pek, J., \& Greenberg, M. T. (2012). Parent-reported attention deficit/hyperactivity symptomatology in preschool-aged children: factor structure, developmental change, and early risk factors. Journal of Abnormal Child Psychology, 40, 1301-1312.

Zahn-Waxler, C., Radke-Yarrow, C. M., Wagner, E., \& Chapman, M. (1992). Development of concern for others. Developmental Psychology, 28, 26-136. 